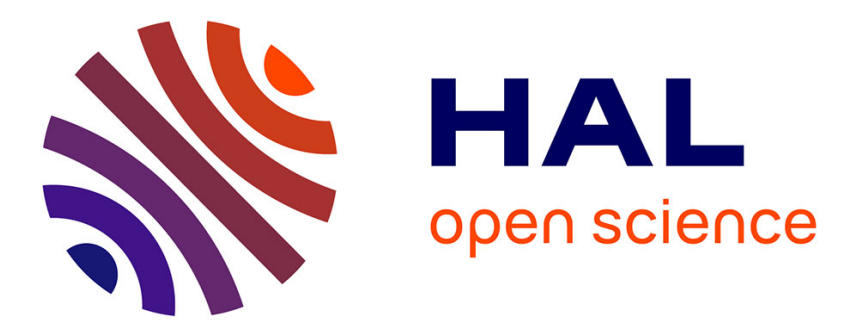

\title{
TEXTURAL AND STRUCTURAL STUDIES OF AEROGELS BY RAMAN SCATTERING AND THERMOPOROMETRY
}

J. Rousset, A. Boukenter, Bernard Champagnon, E. Duval, J. Quinson, M.

Chatelut, J. Dumas, J. Serughetti

\section{To cite this version:}

J. Rousset, A. Boukenter, Bernard Champagnon, E. Duval, J. Quinson, et al.. TEXTURAL AND STRUCTURAL STUDIES OF AEROGELS BY RAMAN SCATTERING AND THERMOPOROMETRY. Journal de Physique Colloques, 1989, 50 (C4), pp.C4-163-C4-166. 10.1051/jphyscol:1989426 . jpa-00229502

\section{HAL Id: jpa-00229502 https://hal.science/jpa-00229502}

Submitted on 1 Jan 1989

HAL is a multi-disciplinary open access archive for the deposit and dissemination of scientific research documents, whether they are published or not. The documents may come from teaching and research institutions in France or abroad, or from public or private research centers.
L'archive ouverte pluridisciplinaire HAL, est destinée au dépôt et à la diffusion de documents scientifiques de niveau recherche, publiés ou non, émanant des établissements d'enseignement et de recherche français ou étrangers, des laboratoires publics ou privés. 
TEXTURAL AND STRUCTURAL STUDIES OF AEROGELS BY RAMAN SCATTERING AND THERMOPOROMETRY

J.L. ROUSSET, A. BOUKENTER, B. CHAMPAGNON, E. DUVAL, J.F. QUINSON*, M. CHATELUT ${ }^{*}, J$. DUMAS ${ }^{*}$ and J. SERUGHETTI*

Laboratoire de Physicochimie des Matériaux Luminescents, CNRS UA-442, Université C. Bernard, Lyon I, F-69622 Villeurbanne Cedex, France * Laboratoire de Chimie Appliquée et de Génie Chimique, CNRS UA-417. Université C. Bernard, Lyon I, F-69622 Villeurbanne Cedex, France * "Département de Physique des Matériaux, CNRS UA-172, Université $C$. Bernard, Lyon I. F- 69622 Villeurbanne Cedex, France

\section{Résumé}

Les rêsultats expérimentaux obtenus par diffusion Raman basse frêquenee et thermoporométrie sur la structure d'aérogels préparés en hilieu basique sont présentés. Les dimensions des unités texturales -ou billes- et des mesopores sont déterminés. Les résultats sont en accord avec une structure fractale uniquement dans les unités texturales.

\section{Abstract}

Experimental results on the structure of base-catalysed aerogels obtained from low frequency Raman sçattering and thermoporometry are presented. The size of textural units or beads and of mesopores are determined. These results are in agreement with a fractal structure only in the textural units.

From very low frequency Raman scattering two principal informations on heterogeneous materials can be extracted : (1) the size of the heterogeneities, (2) the density of vibrational states which depends on the material structure. The light is scattered from the vibrations localized on the surface of the heterogeneities [1]. The frequency of the surface vibrations depends on the size and on the shape of the heterogeneities. In the case of spherical heterogeneities a maximum of Raman scattering related to the surface vibrations occurs at the frequency $\omega_{\max }[1]$ :

$$
\omega_{\max } \simeq 0.8 \mathrm{v}_{\mathrm{o}} / 2 \mathrm{a}
$$

$v_{0}$ is the sound velocity in the heterogeneity and a the radius of the heterogeneities

It has been shown [2] that the Stokes Raman intensity $I(\omega)$ scattered from a fractal at the frequency $\omega$ is given by the following equation :

$I(\omega) /[\mathrm{n}(\omega)+1] \propto \omega^{2} \mathrm{~d} \phi \mathrm{d} / \mathrm{D} \omega^{-1} \mathrm{~g}(\omega)$

When the scattering from the different points in a fractal volume $\mathrm{R}^{\mathrm{D}}$ is incoherent $R$ is the localization length of the fractal vibration of frequency $\omega$ $g(\omega)$ is density of vibrational states, D the fractal dimension, d the fracton dimensionality, $\mathrm{d} \phi$ the superlocalization exponent, which is such that the fracton wave function decays as [3]: $\varphi(r) \sim \exp -\operatorname{ard} \phi$ In the case of coherent scattering it would be found $[4,5]$ :

$I(\omega) /\left[\mathrm{C}(\omega)+\mathbb{D} \propto \omega^{2 \mathrm{~d} \phi \tilde{\mathrm{d}} / \mathrm{D}} \omega^{-\tilde{\mathrm{d}}} \omega^{-1} \mathrm{~g}(\omega)\right.$

Defining the reduced intensity as $I_{\text {red }}$

$(\omega)=I(\omega) \cdot \omega /[\mathbf{n}(\omega)+1]$

the following power-law is obtained :

$$
I_{\text {red }}(\omega) \sim \omega v
$$

Using the relation of $g(\omega)$ versus $\omega$ for a fractal [6]:

$$
g(\omega) \sim \omega \vec{d}-1
$$


the Raman exponent $v$ is :

$$
v=\widetilde{d}\left[\frac{2 d \phi}{D}+1\right]-1
$$

in the case of incoherent scattering . And :

$$
v=\frac{2 \widetilde{d} d \phi}{D}-1
$$

for coherent scattering

Thermoporometry is a thermal method [7,8] for determining the pore radius, the porous volume and the specific surface. This method analyses the conditions of the solidification of a condensate saturating the porous material. It has been shown to be a powerful method to characterise the porous texture of wet gels[9]. However this technique can be extended to the study of aerogels if the preparation conditions of the samples are carefully chosen.

Low frequency Raman scattering and thermoporometry are two complementary techniques for textural and structural studies of porous materials like silica-aerogels.

The silica-aerogels samples were obtained from Airglass (Staffenstorp, Sweden). They were prepared by base catalyzed hydrolysis and condensation of tetramethoxysilane in methanol in presence of ammoniac. The solvent was removed under hypercritical conditions. The density of the samples varied from 0.075 to 0.25 . The experimental configuration to observe the Raman scattering was conventional. The incident 1 ight was emitted from an argon laser. Various 1 ines were used 4545,4880 and $5145 \mathrm{~A}^{\circ}$. The power of the laser varied between 100 and $300 \mathrm{~m} \mathrm{~W}$. A Jobin-Yvon U1000 spectrograph and a photon counting system were used to analyse the scattered light.

For thermoporometry: the filling of aerogels pores by the condensate liquid induces a capillary strain proportionnal to the surface tension between the 1iquid and the skeleton of the aeroge1, and apt to destroy the fragile texture of the sample. In our case the condensate used for thermoporometry is water, liquid with a strong surface tension. To avoid the texture of aerogels to collapse the following procedure has been retained :

a) The aerogel sample is kept in vaporous ethanol during 20 hours, and then filled with liquid ethanol. Ethanol has a low surface tension.

b) The ethanol is slowly exchanged with water, by using ethanol-water mixture of increasing water concentration in order to raise slowly the surface tension until to completely fill the sample with pure water.

In figure 1 the Raman scattering $I(\omega) /[\mathrm{n}(\omega)+1]$ at the foot of the Rayleigh line is shown for the four aerogels samples. The maximum related to the size of the building-blocks or the diameter $2 \mathrm{a}$ of the beads shifts towards the Rayleigh line when the density increases. Using the equation (1) and choosing a sound velocity $v_{0}=4000 \mathrm{~m} / \mathrm{s}$, the diameters of the beads are deduced and given in table-l. The chosen sound velocity in the beads is justified by the density in the beads which is close to 1.8 as determined by Walrafen et a1. [10].

The figure 2 shows the logarithm of the reduced intunsity versus $\omega$. The plots are linear between approximately $30 \mathrm{~cm}^{-1}$ and $200^{-1}$. The slopes are close to 1 for the different aerogels.

From theoretical considerations [1] , the possible values of d are limited :

$$
1<d_{\phi}<1.3
$$

On the other hand SAXS measurements indicate that the studied aerogels are fractal on lengths smaller than $100 \mathrm{~A}^{\circ}$ with a fractal dimension $D \simeq I .9$. Comparison with the Raman scattering measurements (table 1) and also with the electron microscopy [12,13] leads to a fractal structure inside the beads or building blocks.

From equations (6), it is obtained

$$
0.85<\tilde{d}<1
$$

if the Raman scattering is incoherent [13] and

$$
1.45<\widetilde{d}<2
$$

if the Raman scattering is coherent.

Our measurements do not allow to decide if the Raman scattering is coherent or incoherent. However we can assume that in the aerogels the disorder destroys the coherence of the fractal vibrations. Inelastic neutron scattering would bring the solution of this problem. In the case of epoxy-resins and DGEBA comparison beetween Raman scattering and inelastic neutron scattering showed that the Raman scattering is incoherent [14].

Figure 3 shows the pore size distribution curves for the four aerogel samples, obtained from thermoporometry measurements. The result are collected in table 1 . The pore diameters correspond to the maximum of the pore size distribution curve. 
Table 1

\begin{tabular}{|l|c|c|c|}
\hline $\begin{array}{c}\text { Density of } \\
\text { aexoge1 }\end{array}$ & $\begin{array}{c}\text { Diameter of } \\
\text { beads a } \\
\mathrm{A}^{0}\end{array}$ & $\begin{array}{c}\text { Diameter of } \\
\text { mesopores } \\
\mathrm{A}^{\text {o }}\end{array}$ & $\begin{array}{c}\text { Mesoporous } \\
\text { Volume per } 1 \mathrm{~g} \\
\text { of matter }\left(\mathrm{cm}^{3}\right)\end{array}$ \\
\hline 0.075 & $53 \pm 5$ & $100 \pm 5$ & 1.45 \\
0.1 & $61 \pm 5$ & $140 \pm 7$ & 1.64 \\
0.2 & $85 \pm 5$ & $246 \pm 12$ & 2.23 \\
0.25 & $82 \pm 5$ & $254 \pm 12$ & 2.52 \\
\hline
\end{tabular}

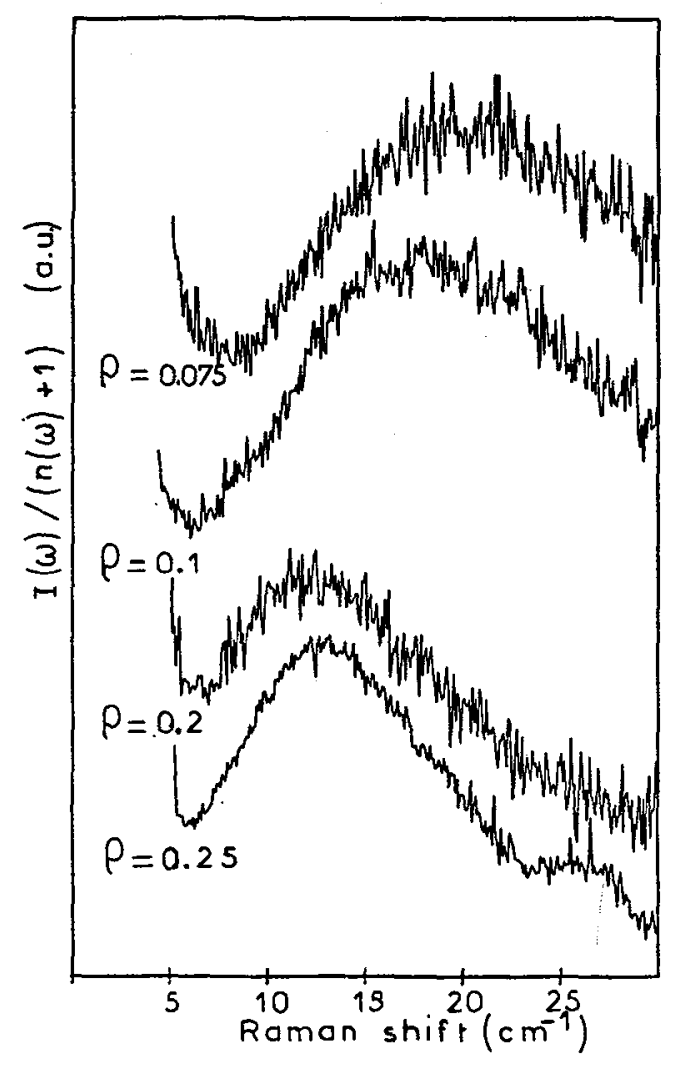

Figure 1 - Low frequency Raman spectra for base catalyzed aerogels of different densities $p$

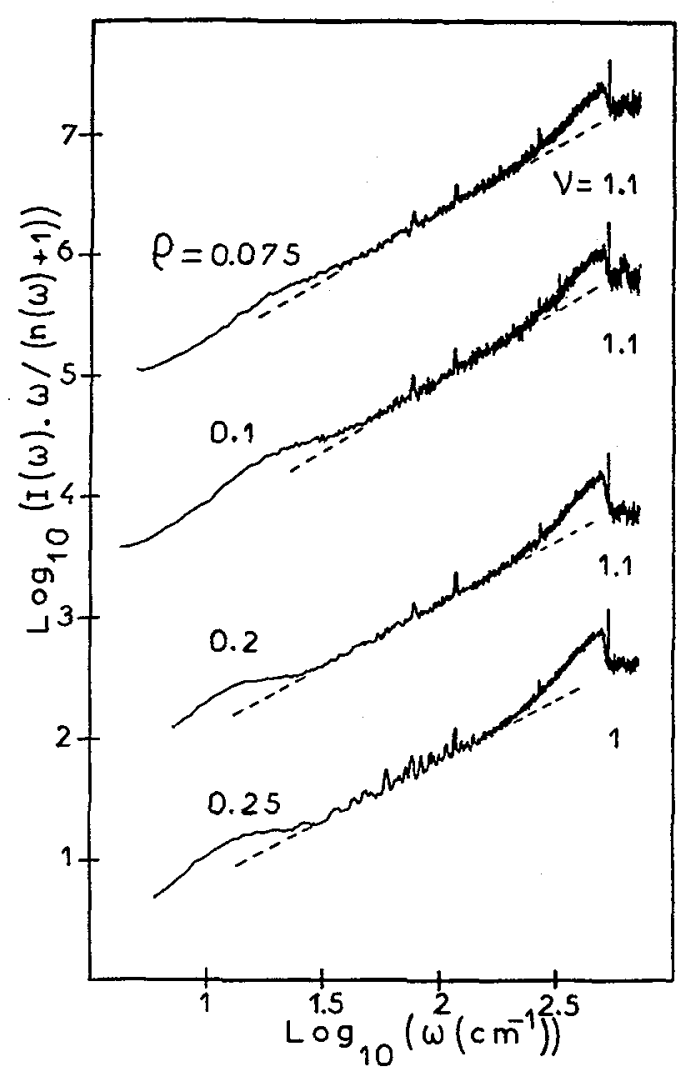

Figure 2 - Log-log plot of the reduced intensity versus $\omega$

The thermoporometry measurements allowed us to determine the characteristics of the mesopores. Comparison between the aerogel density and the mesoporous volume indicatesthat the macroporous volume (diameter of pores larger than $1000 \mathrm{~A}^{\circ}$ ) is dominant.

Comparison between Raman scattering and thermoporometry (table 1) is interesting. The ratio of the size of mesopore over the size of beads varies from 2 to 3 when the density of the aerogel increases. The ratio of the number of beads over the number of pores in the nesostructure goes from 3 to 6 . The density of the mesopores structure (without macropores) is equal to 0.3 . The apparent density of the aerogels is mainly dependent only on the macroporous volume.

The meso-structure would be similar to a non fractal disordered cubic network in which a unit edge would be built with three or four beads. The fractal structure exists only in the beads or building blocks. 


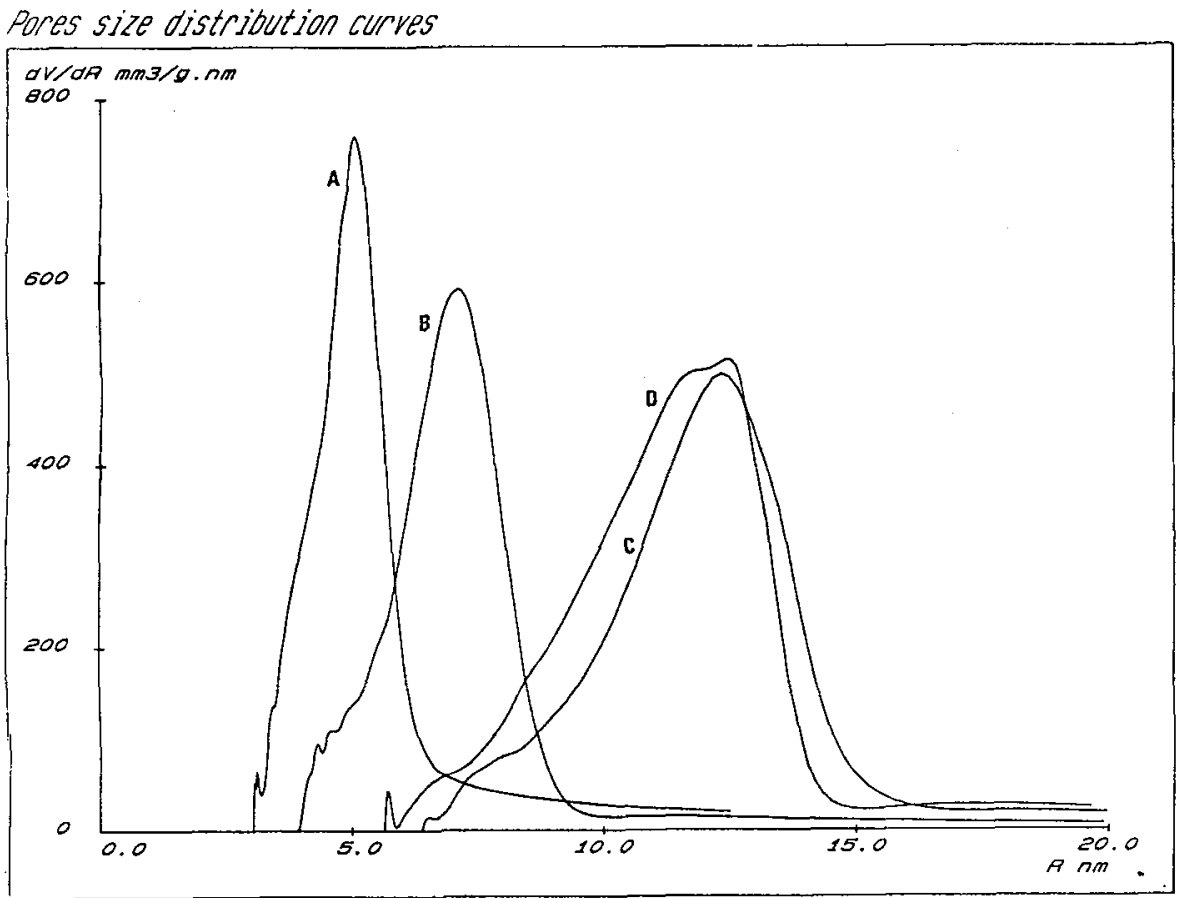

Figure 3 - Pore size distribution as determined from thermoporometry A: $\rho=0.075, B: \rho=0.1, C: \rho=0.2, D: \rho=0.25$

REFERENCES

/1/ DuVAL,E., BOUKENTER, A., and CHAMPAGNON, B., Phys.Rev.1ett. 56 (1986) 2052

/2/ BOUKENTER, A., CHAMPAGNON, B., DUVAL, E., DUMAS, J., QUINSON, J.F., and SERUGHETTI, J. Phys.Rev.lett. 57 (1986) 2381

/3/ ALEXANDER,S., ENTIN-WOHLMAN, O, and ORBACH, R., Phys.Rev. B 32 (1985) 6447

/4/ BOUKENTER, A., CHAMPAGNON, B., DUVAL, E., ROUSSET, J.L., and ROSENBERG, H.M., Phil.Mag. (1989) to be published

/5/ TSUJIMI, Y., COURTENS, E., PELOUS, J., and VACHER, R., Phys.Rev.1ett. 60 (1988) 2757

$/ 6 /$ ALEXANDER, S., and ORBACH, R., J.Phys. (Paris) 1ett.43 (1982) L 625

/7/ BRUN, M., LALLEMAND, A., QUINSON, J.F., and EYRAUD, C., Thermochimie Acta 21 (1977) 59

/8/ QUTNSON, J.F., and BRUN, M., in characterization of Porous Solids 39(1988) 307, E1sevier

/9/ QUINSON, J.F., TCHIPKAM, N., DUMAS, J., BOVIER, C., SERUGHETTI, J., GUIZARD, C., LARBOT, A., and COT, L., J.Non cryst.SoI. 99 (1988) 151

/10/ WALRAFEN, G.E., HOKMABADT, M. S., HOLMES, N.C., NELIIS, W.J., HENNING, S., J. Chem.phys. $82(1985) 2472$

T11/ HARRIS, A.B., AHARONY, A., Europh.1ett. 4 (1987) 1355

/12/ BOURRET, A., Europh.lett; 6 (1988) 731

/13/ BOUKENTER, A., CHAMPAGNON, B., DUVAL, E., ROUSSET, J.L., DUMAS, J., and SERUGHETTI, J., Europh.lett. (1988) to be published

/14/ BOUKENTER, A., DUVAL, E., and ROSENBERG, H.M., J.Phys. C : Solid St 1ett. 21 (1988)L541 